\title{
Design of Automatic Harvest System Monitoring for Oyster Mushroom Using Image Processing
}

\author{
Diana Rahmawati ${ }^{1}$, A. Fiqhi Ibadillah, Miftachul Ulum \\ Electrical Engineering Departement \\ University of Trunojoyo Madura \\ Bangkalan, Madura \\ 1diana_rahmawti@yahoo.com
}

\author{
Heri Setiawan ${ }^{2}$ \\ Weapon Electrical System Departement \\ Indonesian Army Polytechnic \\ Malang, Indonesia \\ ${ }^{2}$ hsetiawan@ymail.com
}

\begin{abstract}
The aim of this study is designing a system which can automatically detects the harvest time of the plant, using data from camera, using image processing. Phase one of our project depends on designing a harvest time decision maker system using image processing. Phase 1, plant grown using Smart greenhouse automation is done. Then, we design integrated system to detect real time harvest time, Ana it is discussed using implementation of IoT and analog devices. In order to detect the harvest time, we use the edge detection algorithms. The result of this study, show quality of the plant, which have $15 \%$ of error rate at the left sector, and $20 \%$ of error rate at the right sector.
\end{abstract}

Keywords - Smart greenhouse; android; image processing; edge detection; harvest

\section{INTRODUCTION}

A specific advantage of the smart greenhouse is that the environment may be controlled in such a way that optimal growing-conditions are obtained. The Smart Greenhouse promise an excelent yields better than in the open field, because of its advantages on climate control. The Smart Greenhouse resulted crops represent a shift from extensive to intensive production. In a smart greenhouse, the plants arrange corresponding to its terms condition. Controlling climate conditions in a greenhouse must be adjusted to the desired conditions. If there is a change in the system, this smart green house must be able to restore the system according to the setpoint again. Its must be able to reduce the surrounding climate disturbances, so that plants can develop in accordance with the conditions set. With this climate change, the sensor will send a report, then the controller responds so that the climate can be controlled like the initial set point.

The main goal of smart green house is so that the conditions in this greenhouse are in accordance with the requirements of the flower plants that are maintained. in this green house sensors are installed, such as temperature, humidity, soil humidity, $\mathrm{pH}$, and $\mathrm{CO} 2$ levels in the greenhouse. the data from this sensor is then read by the system, then becomes input for the controller. by using this controller, the system is then set using an algorithm according to the method used, so the system works perfectly, according to the desired input.

This smart green house automation system promises an effective farming system. Plants that cannot grow in certain areas, can be developed in the area, using smart green house automation. Climates that were previously not achievable provided that plants grow and produce good crops, can be controlled using sensors and control algorithms. This will produce crops with high productivity, thus helping farmers to increase their yields. Increasing research and development on a variety of sensing, actuation and information technology hardware and software reveals the interest of having automated agriculture parallel to the controlled environment benefits. Greenhouse automation is also associated with better management through process optimization.

One of the aim of the smart green house Technology is the stability of plant production. Green house is in a closed environment, so that all are conditioned to be able to meet the requirements of plant growth. all parameters are controlled, such as temperature, soil humidity, humidity, light intensity, to support the success of plant growth, resulting in a quality harvest. besides that it can also control pests and diseases, so that plants can be protected more. Here, the system is an application oriented. The phase one of our project depends on developing an image processing algorithm to detect harvest time in plants. In step 1 plant grown is done. In phase 2 the embedded system is constructed and a solution for the detected harvest time is discussed using implementation of IoT and analog devices. In the end an application is implemented in the future so that the Iot module sends user about the harvest time and the end using the data to send information to the relay circuit to provide harvest time reminder. So through this research we can directly help the farmer. By using the automated agricultural inspection, farmer can give potentially better and accurate productivity. With the help of this technique, different good quality of crops can be used. [1]

Planting oyster mushrooms requires a lot of attention so that the fungus can develop properly. One aspect of oyster mushroom disease is to provide the right plant environment. If temperature, humidity and freedom are not adequate, our mold blocks will dry out and produce no fruit. We must provide an adequate environment for fungi, one of which is high humidity, especially adequate watering. Although different mushrooms have their own unique environmental requirements, once we have a basic grow area set up you can tailor it to the specific species we are trying to grow. Smart Green House Automation is an embedded system to monitor and control the environment parameters of an oyster mushroom's green house. It is necessary to design a fuzzy control system to monitor various parameters like 
Temperature level, Soil moisture level, Humidity level, Light Intensity and $\mathrm{CO}_{2}$ level]. The main objective of this paper is to design a Smart Fuzzy Green House Automation For Oyster Mushroom Cultivation. The system provides a real time control system which monitors and controls all the activities of the smart greenhouse system perfectly. By continuously monitoring the status of the soil, we can control the flow of water and thereby reduce the wastage. This smart green house automation System also presents the communication interface. The data from the sensor can be sent further for analysis purpose. Using this automation, can save energy, water to increase production and the most important is to increase profit [2].

The aim of image processing project is to recognize objects in a document image segmentation or a complex scene. Edge detection is one of the first steps[3]. Edge detection algorithms can detect an image intensity and/or color with strong transitions. These transitions are characteristic of object edges, region segmentation, text finding and object recognition. Researchers have concentrated in the past few decades on devising algorithms for grayscale image understanding [4]. There are many benefits in using color images. They can make the increase in the quantity of information that can be used for more accurate processing, object location, and the possibility of processing images.

With image processing, we can design a system that follows more closely how the human visual system perceives color objects. To that end, the physical processes that underlie the optical effects have been studied. From the research, the result is derived from a physics-based approach based on the Dichromatic Reflection Model introduced by Shafer in 1985 [5]. Physical processes involved in the image formation stage have not been a strong point of interest in the traditional line of computer vision research [6]. Generally, the proposed algorithm for harvest time image processing has three phase: First, image segmentation process, then object-based analysis process and color features analysis process. Then they sent the data to IoT for the notification.

\section{LITERATURE REVIEW}

\section{A. Smart Green House}

Fig. 1 present a process of Smart Green House Monitoring System. In this Smart Green House Monitoring System the data are collected from the wireless sensor nodes. Nextxt process is to analyze the data for an expert climate control. At this case, we use fuzzy logic in order to optimize water usage and energy consumption. To control the fuzzy logic parameter is used and implemented using Arduino board. The data from different sensors collected to frequently monitor light intensity, humidity, temperature, and soil moisture, in the smart greenhouse. The output from the greenhouse climate is received by the sensor node, it is transmitted to the wireless node through a wireless protocol. This Smart Green House Monitoring System uses nodemCu wireless module for data transmission from the end devices to the web server node. Using the data from the web server node, the farmer can monitor and control the smart greenhouse climate easily using android application.[7].

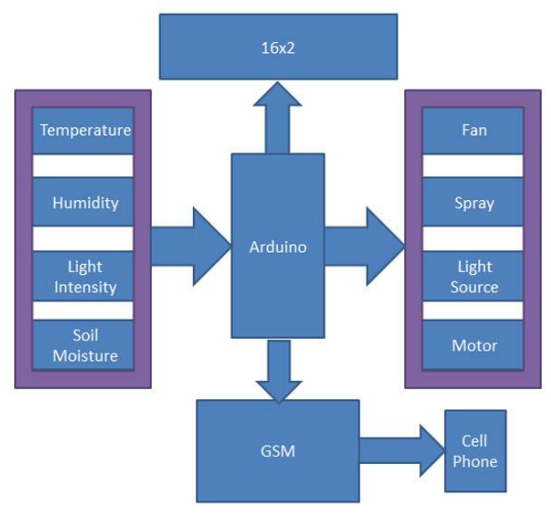

Fig. 1. Process of Smart Green House Monitoring System

\section{B. Edge Detection}

In image processing science, edge detection has become an important topic in image management because of its ability to provide appropriate information from images and provide interesting object boundaries. It provide a basic operation to get information about an image, such as its size, morphology and texture. Edge detection technique is showed the most common method to detect significant discontinuities in the values of intensities of an image. The technique is acomplished by taking spatial derivatives of first and second order (using the gradient and Laplacian). This spatial derivatives show the image non smooth changes in the function $f(x, y)$ can be determined with the derivatives equation. The operators that represent edges are particularly expressed by partial derivatives.

By using edge detection, result that consists of binary image the pixels where hard changes have tauke place appear bright, while the other pixels remain dark. A significant degradation on the amount of information, as this output in change permits while defending the important structural properties of the image. The gradient set as the first derivative, which is able to assign a change in the intensity function. It's through a one-component vector (hint) pointing in the hint of maximum growth of the image's intensity. The gradient of a two dimensional intensity function $f(x, y)$ is defined as[17]:

$$
\nabla f \equiv \operatorname{grad}(f)=\left[\begin{array}{l}
\frac{\partial f}{\partial x} \\
\frac{\partial f}{\partial y}
\end{array}\right]
$$

The magnitude of this vector is:

$$
\begin{aligned}
\nabla f & =\operatorname{mag}(\nabla f)=\sqrt{g_{x}^{2}+g_{y}^{2}} \\
& =\sqrt{\left(\frac{\partial f}{\partial x}\right)^{2}+(\partial f / \partial y)^{2}}
\end{aligned}
$$

And the direction is given by the angle:

$$
\alpha(x, y)=\tan ^{-1}\left(\frac{g_{y}}{g_{x}}\right)
$$




\section{METHODOLOGY}

Image processing using edge detection was developed in 1960 and 1970 [8, 9]: Roberts [10], Prewitt [11], and Sobel [12]. these methods are widely used for several different applications. Although many new methods emerge, this simple, old detection method can still be used effectively[13]. In this study, several standard methods of edge detection are carried out gray-level edge detectors for color image processing. Color image processing is explained in this section.

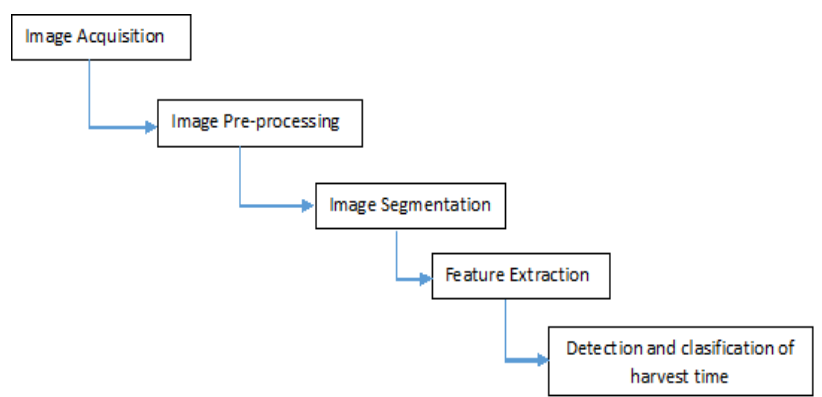

Fig. 2. System Model : Harvest time using image processing

Image Acquisition: In this section, first the camera works. The camera captures the image, and then we analyze the captured image. This process is named image acquisition. Images processed in RGB form, namely red, green, and blue. then applied a separate color transformation structure for captured RGB images. CCD array sensors that are analyzed in the camera, are in the form of a rough array. some digital light sensing instrumentation and digital cameras using CCD sensors. The CCD sensor response is directly proportional to the integral of the energy projected to the sensor, requiring low noise images, such as those of astronomical applications. In order to reduce the noice, we let the sensor integrate with the input light signal over minutes or even hours, until we get the right noice value. Then we can complete the image can be obtained by focusing the energy pattern onto the surface of the array, because the sensor array is two dimensional. [14].

Image Pre-Processing: To get the image region, we crop the plant image. This pre-processing techniques aim is to remove noise in image. then we use smoothing filter to make the image smooth. Its called as image smoothing. In order to increase the contrast, image enhancement is done.

Image Segmentation: The whole image segmented in defect region, its call image segmentation. It may also be used to segment based on same features or certain similarity. this section can also be used for strengthening based on courage or other obstacles. this paper uses the K-mean segmentation with the otsu's threshold method and then converts RGB images into HIS models, etc. In the process of image segmentation, an image is partitioning into meaningful parts. This process is perhaps the most researched and most important topic in image analysis. The image analysis in image segmentation process can be attributed to the importance of segmentation, whith the fact that a universal method does not exist that can segment all images [15].
Feature Extraction: In order to identify an object in an image, we use feature extraction. This process plays an important role in the image analysis. In many application of image processing feature extraction is used so that it simplifies the further processing. In plant harvest detection, the variable that can be used are: color of the plant, texture, morphology, edges etc. In harvest detection they think over the variable : color, texture and morphology as a feature for harvest detection. This research have found that morphological result of the feature extraction gives better result than the other features. How the colour is distributed in the image, the roughness, hardness of the image is texture definition [16]. High-level feature extraction attentions how to find shapes in computer images.

According to the output which they generate, several digital image processing techniques have been classified, base on the problem. Then it can be classified base on supervised or unsupervised methods, and base on using crisp or fuzzy techniques. When we use a digital image (such as classification, edge detection, segmentation and hierarchical segmentation), different problems should be formally classified when trying to recognize an object. Color segmentation output and the resulting image is not always appropriate. This detection system can only detect, but no photo objects were found [17].

\section{RESEARCH RESULTS}

Fig. 3 show the results of edge detection calculations using software. The resulting value shows an indication of the extent to which digital processing results approach the ideal image.
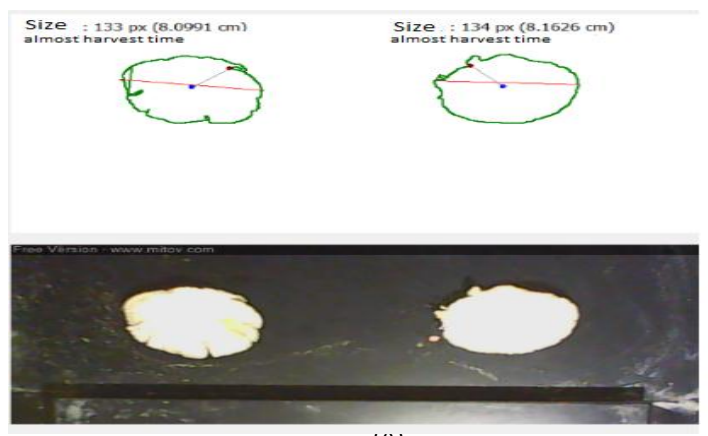

(d)

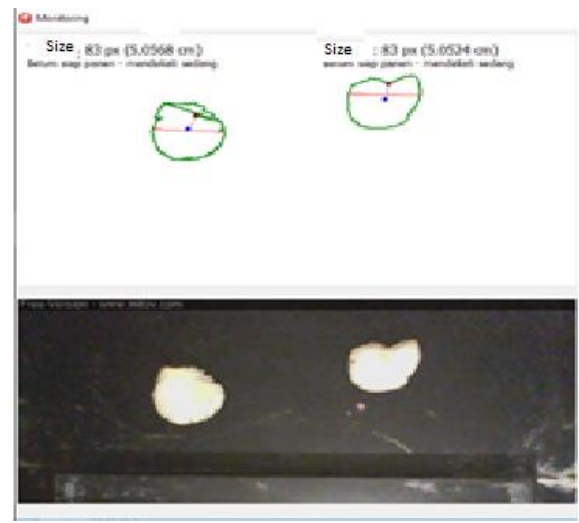

(b) 


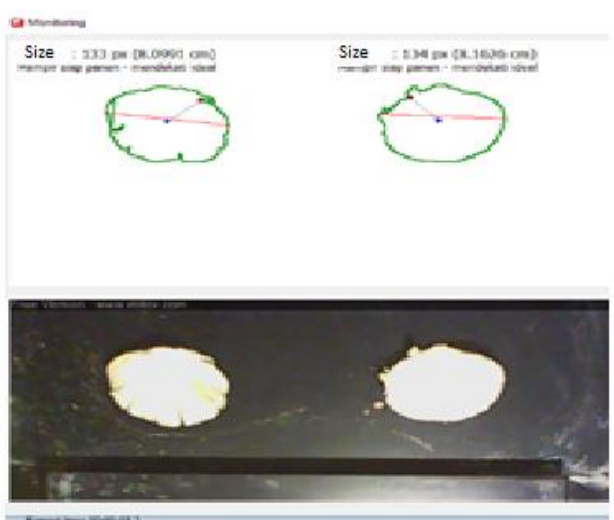

(c)

Fig. 3. Data Image

Green objects are the result of object image processing, and red lines are used to determine the object's midpoint. The test results for several samples of oyster mushrooms are as follows:

TABLE I. TESTING RESUlTS AT THE LEFT SECTOR

\begin{tabular}{|c|c|c|c|c|}
\hline \multirow{2}{*}{ NO. } & \multicolumn{3}{|c|}{ Testing Results At The Left Sector } \\
\cline { 2 - 5 } & $\begin{array}{c}\text { Size on the } \\
\text { application } \\
(\boldsymbol{p} \boldsymbol{x} / \boldsymbol{c m})\end{array}$ & Category & quality & Result \\
\hline 1. & $100 / 6,09$ & $\mathrm{HI}$ & $\mathrm{A}$ & $\mathrm{HSP}$ \\
\hline 2. & $120 / 7,3$ & $\mathrm{I}$ & $\mathrm{A}$ & $\mathrm{SP}$ \\
\hline 3. & $125 / 7,6$ & $\mathrm{I}$ & $\mathrm{B}$ & $\mathrm{SP}$ \\
\hline 4. & $110 / 6,6$ & $\mathrm{I}$ & $\mathrm{A}$ & $\mathrm{SP}$ \\
\hline 5. & $116 / 7,1$ & $\mathrm{I}$ & $\mathrm{A}$ & $\mathrm{SP}$ \\
\hline 6. & $97 / 5,9$ & $\mathrm{HI}$ & $\mathrm{A}$ & $\mathrm{HSP}$ \\
\hline 7. & $106 / 6,4$ & $\mathrm{I}$ & $\mathrm{A}$ & $\mathrm{SP}$ \\
\hline 8. & $86 / 5,0$ & $\mathrm{HI}$ & $\mathrm{A}$ & $\mathrm{HSP}$ \\
\hline 9. & $94 / 5,7$ & $\mathrm{HI}$ & $\mathrm{B}$ & $\mathrm{HSP}$ \\
\hline 10. & $73 / 4,4$ & $\mathrm{~S}$ & $\mathrm{~B}$ & $\mathrm{BSP}$ \\
\hline
\end{tabular}

TABLE II. COMPARISON OF MEASUREMENTS BETWEEN APPLICATION AND RULER

\begin{tabular}{|c|c|c|c|}
\hline \multirow{2}{*}{ No. } & \multicolumn{3}{|c|}{$\begin{array}{c}\text { Comparison Of Measurements Between Application And } \\
\text { Ruler }\end{array}$} \\
\cline { 2 - 4 } & Size on application (cm) & $\begin{array}{c}\text { Real Size } \\
(\mathbf{c m})\end{array}$ & Margin \\
\hline 1. & 6.09 & 6 & 0.09 \\
\hline 2. & 7.3 & 7.5 & 0.2 \\
\hline 3. & 7.6 & 7.5 & 0.1 \\
\hline 4. & 6.6 & 6.5 & 0.1 \\
\hline 5. & 7.1 & 7 & 0.1 \\
\hline 6. & 5.9 & 6 & 0.1 \\
\hline 7. & 6.4 & 6.5 & 0.1 \\
\hline 8. & 5.0 & 5 & 0 \\
\hline 9. & 5.7 & 6 & 0.3 \\
\hline 10. & 4.4 & 4 & 0.4 \\
\hline
\end{tabular}

By using a tolerance of 0.149 from the data above table, it is known that from 10 oyster mushroom sample tests, the system has failed as much as 3. By using image processing, the presentation of success :

Total Testing : 10, Success : 7, Failed: 3 .

Error Rate $=3 /(7+3+10) \times 100 \%=0.15=15 \%$
TABLE III. OBJECT TESTING RESULTS AT THE RIGHT SECTOR

\begin{tabular}{|c|c|c|c|c|}
\hline \multirow{2}{*}{ No. } & \multicolumn{3}{|c|}{ Testing Results At The Right Sector } \\
\cline { 2 - 5 } & $\begin{array}{c}\text { Size on the } \\
\text { application } \\
(\boldsymbol{p} \boldsymbol{x} / \boldsymbol{c m})\end{array}$ & Category & quality & Result \\
\hline 1. & $98 / 5,9$ & HI & B & HSP \\
\hline 2. & $96 / 5,8$ & HI & A & HSP \\
\hline 3. & $80 / 4,8$ & S & A & BSP \\
\hline 4. & $128 / 7,7$ & I & B & SP \\
\hline 5. & $96 / 5,8$ & HI & B & HSP \\
\hline 6. & $94 / 5,6$ & HI & A & HSP \\
\hline 7. & $72 / 4,3$ & S & A & BSP \\
\hline 8. & $107 / 6,5$ & I & A & SP \\
\hline 9. & $74 / 4,4$ & S & B & BSP \\
\hline 10. & $104 / 6,3$ & I & A & SP \\
\hline
\end{tabular}

TABLE IV. COMPARISON OF MEASUREMENTS BETWEENAPPLICATION AND RULER

\begin{tabular}{|c|c|c|c|}
\hline \multirow{2}{*}{ No. } & \multicolumn{3}{|c|}{$\begin{array}{c}\text { Comparison of Measurements Between } \\
\text { Application And Ruler }\end{array}$} \\
\cline { 2 - 4 } & Size on application (cm) & $\begin{array}{c}\text { Real Size } \\
(\mathbf{c m})\end{array}$ & Margin \\
\hline 1. & 5,9 & 6.4 & 0,5 \\
\hline 2. & 5,8 & 6 & 0,2 \\
\hline 3. & 4,8 & 5 & 0,2 \\
\hline 4. & 7,7 & 7.5 & 0,2 \\
\hline 5. & 5,8 & 5.5 & 0,3 \\
\hline 6. & 5,6 & 5.5 & 0,1 \\
\hline 7. & 4,3 & 4.5 & 0,2 \\
\hline 8. & 6,5 & 6 & 0,5 \\
\hline 9. & 4,4 & 4 & 0,4 \\
\hline 10. & 6,3 & 6.5 & 0,2 \\
\hline
\end{tabular}

From the data of the table, it is known that from 10 oyster mushroom sample tests performed, the system has failed as much as 4. By using image processing, the presentation of success is as big as:

Test Total: 10, Success 6, Failed 4.

Precission $=6 /(6+4) \times 100 \%=0.6=60 \%$ $\begin{aligned} \text { Acuracy }= & (6+10) /(6+4+10) \times 100 \%=(16) / 20 \times 100 \%= \\ & 80 \%\end{aligned}$

Error Rate $=4 /(6+4+10) \times 100 \%=0.2=20 \%$

Note :

S : Medium

HI : Almost Ideal

I : Ideal

BSP : Not Ready to Harvest yet

HSP Almost ready to harvest

SP Ready to harvest

The result of all the sensors is displayed in LCD through the microcontroller and it sends the message when the threshold goes beyond the certain level to our android phone. In the plant image processing, we are using edge detection do detect the harvest time. The result of the plant image processing is sent to the Programmable Interface Controller PIC) micro controller. The microcontroller detects the 
presence of the signal and sends a message to the mobile via a nodemCu.

\section{CONCLUSION}

The result of this study, show quality of the plant, which have $15 \%$ of error rate at the left sector, and $20 \%$ of error rate at the right sector. This harvest decision-making system in this reseach has not produced optimal results, then it will be tested and read based on color differences. This should be an area of future focus.

\section{SUGGESTION}

In order to improve the harvest decision-making system performance, it is better to use especially the sobel and canny edge detection operators for edge detection. [18]. Next we will connect this research with android to get real time monitoring.

\section{ACKNOWLEDGMENT}

Special appreciation for Indonesian RISTEKDIKTI who funding this research at scheme "Penelitian Strategis Nasional Institusi" and Trunojoyo University of Madura for the support.

\section{REFERENCES}

[1] M.R. Badnakhe and P.R. Deshmukh, "Infected Leaf Analysis and Comparison by Otsu Threshold and k-Means Clustering," Int. J. Adv. Res. in Comput. Sci. and Software Eng., vol. 2(3), 2012

[2] D. Rahmawati, M. Ulum, and H. Setiawan, "Design of Smart Fuzzy Green House Automation For Oyster Mushroom Cultivation," Proc. Int. Joint Conf. Sci. And Technol., 2018.

[3] Robert M. Haralick and Linda G. Shapiro. Computer and Robot Vision, vol. 1, AddisonWelsey: Reading, MA, 1992.

[4] A.K. Jain, Fundamentals of Digital Image Processing, Prentice Hall, Inc., Englewood Cliffs, NJ, 1989.

[5] G.J. Klinker, S.A. Shafer, and T. Kanade, "A Physical Approach to Color Image Understanding," Int. J. Comput. Vis., vol. 4, No. 1, pp. 738, 1990.

[6] S. Bankar, A. Dube, P. Kadam, S. Deokule, "Plant Disease Detection Techniques Using Canny Edge Detection \& Color Histogram in Image
Processing," (IJCSIT) International Journal of Computer Science and Information Technologies, vol. 5 (2) , 2014, 1165-1168

[7] D. Rahmawati, M. Ulum, and H. Setiawan, "Design of Android Base Fuzzy Wireless Sensor Network for mini Smart Green House", IOP Conf. Series: J. Phys.: Conf. Series 1028 (2018) 012051

[8] S.A. Shafer, "Using color to separate reflection components," COLOR research and application, vol. 10, No. 4, pp. 210-218, 1985. Also available as technical report TR 136, Computer Sciences Department, University of Rochester, NY, April1994.

[9] R. C. Gonzalez and R. E. Woods, Digital Image Processing. AddisonWesley, 1993

[10] L. G. Roberts, Machine Perception of Three Dimensional Solids Optical and Electrooptical Information Processing, MIT Press, Cambridge, MA, 1965, pp. 159-197.

[11] L. G. Prewitt, "Object Enhancements and Extraction," in Picture Processing and Psychopictorics, B. Lipkin and A. Rosenfeld (eds.), Academic Press, New York, NY, pp. 75-149. 1970.

[12] I. E. Sobel, Camera Models and Machine Perception, Ph.D. Thesis, Electrical Engineering Department, Stanford University, Stanford, CA, 1970.

[13] M. Heath, S. Sarkar, T. Sanocki, and K. Bowyer. "Comparison of Edge Detectors: Methodology and Initial Study," J. Computer Vison and Image Understanding, vol. 69, no. 1, pp. 38-54, January 1998.

[14] H. Al-Hiary, S. Bani-Ahmad, M. Reyalat, M. Braik, and Z. AlRahamneh, "Fast and Accurate Detection and Classification of Plant Diseases", Int. J. Comput. Appl., pp. 975-987 vol. 17, no.1, March 2011.

[15] Chunxia Zhang, Xiuqing Wang and Xudong Li, "Design of Monitoring and Control Plant Disease System Based on DSP\&FPGA," 2010 Second International Conference on Networks Security, Wireless Communications and Trusted Computing. 2010.

[16] Meunkaewjinda, A., P. Kumsawat, K. Attakitmongcol and A. Srikaew, 2008. "Grape leaf disease detection from color imagery using hybrid intelligent system", Proceedings of ECTI-CON 2008

[17] C. Guada, D. Gomez, J.T. Rodrıguez, J. Yanez, J. Montero, “Classifying image analysis techniques from their output”, Int. J. Comput. Intell. Syst., vol. 9, Supplement 1, pp. 43-68, Co-published by Atlantis Press and Taylor \& Francis. 2016.

[18] Y. Yang, "Color edge detection and segmentation using vector analysis," Master's thesis, Electrical and Computer Engineering, University of Toronto, Toronto, Canada, 1995. 